\title{
Assessment Model of Sudden Oil Spill Pollution in South \\ China Sea Navigation Area Based on the Theory of Community of Marine Destiny
}

Yanan Qu*

School of Marine Law and Humanities, Dalian Ocean University, Dalian 116023, China

${ }^{*}$ Corresponding author: Yanan Qu

*to whom all correspondence should be addressed: e-mail: 13624252725@163.com

\section{GRAPHICALABSTRACT}

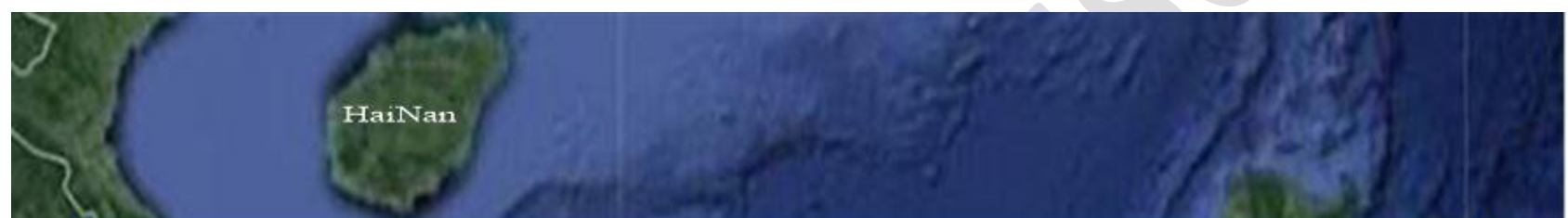

\section{Sudden Oil Spill Pollution in South China Sea Navigation Area}

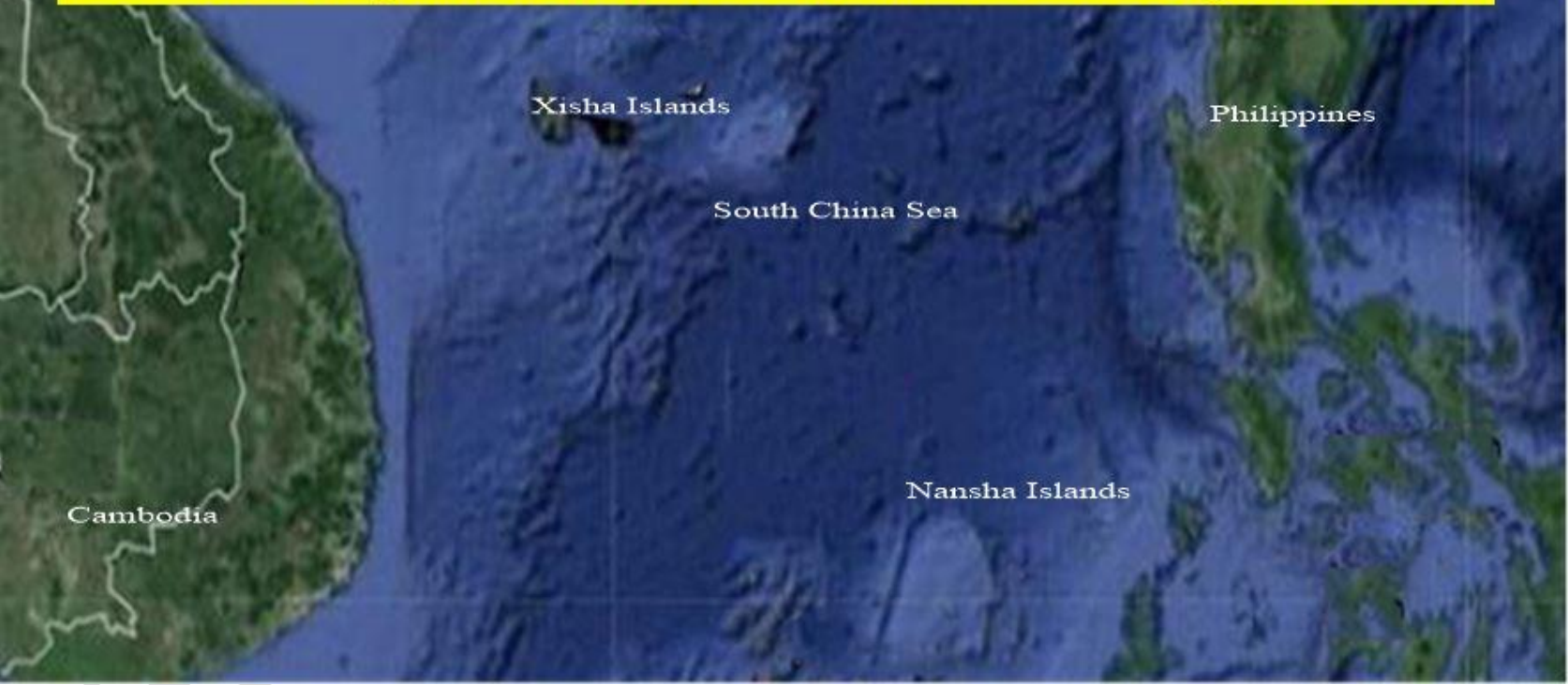

\section{Abstract}

In order to solve the problems of poor accuracy and long time-consuming of traditional methods in the assessment of sudden oil spill pollution from ships, this paper takes the navigation area in the South China Sea as the research object and proposes to build the assessment model of ship oil spill pollution. Based on the analysis of the transportation advantages of the South China Sea navigation area, the probability of ship collision and the relationship between the probability of ship oil spill and the ship tonnage are obtained. Based on the probability of ship oil spill in the South China Sea navigation area, the evaluation index system of oil spill pollution in the South China Sea navigation area is constructed to determine the oil spill pollution index and pollution level, and to determine the oil spill pollution level The weight of oil pollution index is 
used to build the assessment model of sudden oil spill pollution in South China Sea navigation area. The experimental results show that the accuracy of the evaluation model is always maintained at $90 \%$ and the evaluation time is short.

Keywords: Marine community of common destiny theory; oil spill pollution assessment; pollution weight; evaluation model

\section{Introduction}

Shipping industry plays an important role in the rapid development of global economy and society. Because of its low transportation cost and relatively high safety factor, about $90 \%$ of the global trade and transportation activities are completed by shipping, and ships have become the main transportation carrier of Global trade (Jing et al., 2019). However, in the process of shipping, due to the bad weather conditions, the negligence of operators, the narrow channel and the increase of ship traffic density, the sudden traffic accidents of ships occur from time to time, which has brought great damage to human life and property and marine environment (Xue et al., 2018). Among them, the South China Sea navigation area is an important water transport hub in China. The harmful substances caused by ship accidents, especially the marine environmental hazards caused by oil and its related products leakage, have been widely concerned by relevant organizations, government departments, research institutions and the public (Wang et al., 2020). Under the theory of community of common destiny, it is of great significance to evaluate the oil spill pollution from ships. Therefore, researchers in this field have done a lot of research.

The risk assessment method of oil spill pollution based on index method is proposed (Zhang et al., 2019). Taking a port area in Guangzhou as an example, the improved oil spill risk index model is established in five ports of the port area. Compared with the calculation results of the improved model and the evaluation results of the risk matrix method, there is no obvious difference in the risk matrix of the five terminals, and the calculation results of the method are obviously different, It is verified that the evaluation model with oil spill risk index as index is more suitable for oil spill pollution risk assessment of port area (He et al., 2018). The method is simple to operate and takes less time to evaluate oil spill pollution in seaport area. However, the model constructed by this method takes into account a narrow range of regions, which is not conducive to its wide application. A method for evaluating marine oil spill pollution based on biomarkers was proposed (Sha et al., 2018). Based on the definition and classification of biomarkers, this paper analyzes the application characteristics and research status of different kinds of biomarkers in marine oil spill pollution monitoring and evaluation at home and abroad, and the typical methods and important significance of comprehensive application of multiple biomarkers, summarizes and points out the research direction of oil spill pollution assessment in the future, It includes screening biomarkers with high specificity and sensitivity according to the characteristics of marine oil spill pollution, and the establishment of marine oil spill pollution early warning system based on biomarkers (Wang et al., 2020). This method can effectively improve the accuracy of oil spill pollution assessment, and analyze according to different biomarkers, but the timeliness of this method is poor. An assessment method of pollution level of oil spill on the sea based on Improved AHP and extension theory is proposed (Zhang and Liu, 2018). By constructing the evaluation index system of marine oil spill pollution, introducing matter-element extension theory and improved AHP, the evaluation model of oil spill pollution level based on Improved AHP and extension theory is established to evaluate the degree of marine pollution. However, the method does not consider the sudden oil spill on the sea, which leads to the poor real-time performance of the method.

In view of the shortcomings of the above methods, this paper proposes to build an assessment model of ship 
oil spill pollution to evaluate the sudden oil spill pollution in the South China Sea navigation area. The technical route of this paper is as follows.

(1) By analyzing the transportation advantages of the South China Sea navigation area, the probability of ship collision in the navigation area is obtained, and the relationship between the probability of ship oil spill and oil spill and ship tonnage is obtained;

(2) Based on the probability of ship oil spill in the South China Sea navigation area, the evaluation index system of oil spill pollution in this area is constructed, and the pollution index and pollution level are determined;

(3) On this basis, the weight of oil spill pollution index is determined, and the assessment model of sudden oil spill pollution in South China Sea navigation area is constructed.

(4) Experimental analysis.

(5) Conclusion and future prospects.

\section{Probability analysis of ship spill accident in the South China Sea Navigation Area}

\subsection{Analysis of transportation advantage in the South China Sea Navigation Area}

The South China Sea is composed of Dongsha, Nansha, Xisha and Zhongsha. The South China Sea is the second busiest maritime navigation area in the world. According to a 2006 study by the Ministry of land and communications of Japan, the number of ships passing through the Strait of Malacca accounted for about $15 \%$ of the global total in 2004, which was 94000 . Among them, $32 \%$ are container ships, $25 \%$ are oil tankers, $15 \%$ are cargo ships, $15 \%$ are bulk carriers, and the rest are LNG ships and other ships. According to the estimation of the United Nations Conference on Trade and development, in 2010, there were about 117000 ships with a total of about 4.7 million dwt passing through the Strait of Malacca. Of the 8.4 million global shipping volume in that year, more than half of the cargo volume was transported from the South China Sea. The vast majority of these goods crossing the Strait of Malacca go to their destinations via the South China Sea. For China, Spratly Islands is also an important channel for maritime trade. Of the 39 routes leading to foreign countries in China, 21 pass through the Spratly Islands sea area, and 60\% foreign trade transportation passes through Spratly Islands.

The importance of the South China Sea is also reflected in the fact that it is a transportation channel for some important commodities. According to the statistics of relevant departments, crude oil and natural gas, which account for about one third of Global trade volume, are transported through the South China Sea every year. On average, about 14 million barrels of oil are transported through the South China Sea every day. Its geographical location on the map is shown in Figure 1. 


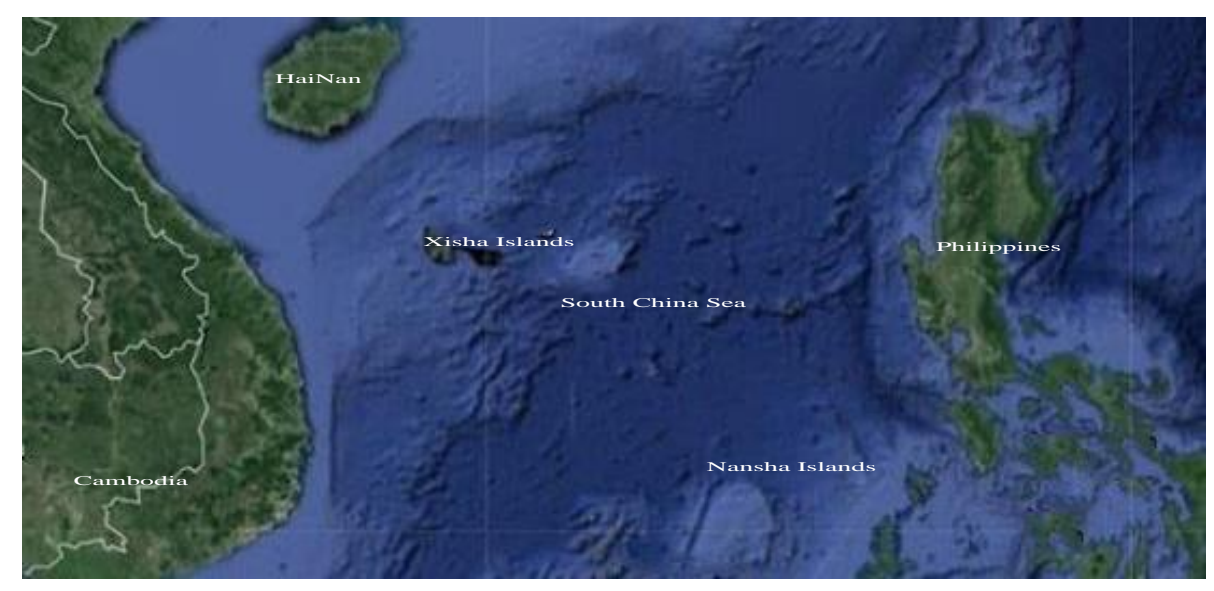

Figure 1. Geographical location of navigation area in the South China Sea

\subsubsection{Oil transport advantages in the navigation area of the South China Sea}

In terms of oil transportation, the Strait of Malacca is the shortest sea transportation route between Asia and the Persian Gulf. According to records, in 2011, an average of 12.8 million barrels of crude oil entered the region every day, and the amount of crude oil transported through the South China Sea navigation area was very large, showing the crude oil transportation capacity of the South China Sea navigation area (Dong et al., 2018).

\subsubsection{Natural Gas transport advantages in the South China Sea Navigation Area}

The South China Sea region is an important area of global LNG transportation, and the liquefied petroleum gas transported through the South China Sea accounts for half of the global natural gas (Gan et al., 2018).

\subsubsection{South China Sea navigation area iron ore transport advantages}

The South China Sea is also the center of iron ore transportation. In the consumption demand of the world's major iron ore exporting countries, Asia accounts for the vast majority. Iron ore transported to the Far East by sea has three routes. One is the India sea entering the South China Sea through the Malacca Strait. The second one is from mainland China, which has reached the west coast of Australia through the South China Sea. Three is from Chinese mainland to Taiwan, from Luzon island to (Li et al., 2018).

It has important advantages in oil, gas and iron ore transportation, and is an important path and hub for various resources to flow into Asia. It is of great significance to analyze and manage the sudden oil spill pollution.

\subsection{Determination of ship probability in South China Sea Navigation Area}

The traffic density in the South China Sea navigation area is high, and the probability of collision between ships is high. There are about 3.6 million ships per year in the global sea area, with a traffic density of about 10 million square kilometers. A large number of ships are concentrated in the navigation area of the South China Sea, and the collision probability of ships sailing in the navigation area is analyzed (Toz and Koseoglu, 2018). 
Assuming that the traffic density of ships in the South China Sea navigation area is 220 vessels / million square kilometers, the correction coefficient of the frequency of ship collision is as follows:

$$
S_{i}=\frac{\vartheta}{220}
$$

In the formula, $S_{i}$ representing the frequency of ship collisions,$\vartheta$ represents the traffic density of the navigation area in the South China Sea. Under the correction of collision coefficient, the probability of oil spill pollution can be obtained as follows:

$$
P_{i}=\bar{P}_{i} \times S_{i}
$$

In the formula, $P_{i}$ represents the frequency of collision, $\bar{P}_{i}$ represents the average frequency of collision.

Due to the influence of weather factors, ships sailing in the South China Sea collide, resulting in oil spill (Liu et al., 2016). The visibility of maritime traffic is an important factor affecting the normal navigation of ships.

It is assumed that the correction coefficient of visibility in the navigation area of the South China Sea is $R_{i}$, Then, the collision and oil spill incidents of ships in this area are as follows:

$$
\varphi_{i}=\bar{P}_{i} \times R_{i}
$$

On the basis of the above analysis, the probability of oil spill pollution is as follows:

$$
R_{i}=5.2 \times \varepsilon+0.9
$$

In the formula, $\varepsilon$ represents poor visibility weather probability.

When sailing in the South China Sea navigation area, the main cause of oil spill pollution in the sea area is ship collision (Yang et al., 2020). The main factors affecting the occurrence of the incident include the traffic density and visibility at sea. The determination of oil spill pollution sources in the South China Sea navigation area is an important link in the analysis of ship oil spill pollution in the South China Sea navigation area (Bayik and Altin, 2017).

\subsection{Probability analysis of ship oil spill pollution in South China Sea Navigation Area}

Oil spill is not inevitable after ship collision in the South China Sea navigation area. The probability of oil spill during the 10 years from 2000 to 2010 is shown in Table 1:

Table 1. Probability of oil spills from collisions between 2000 and 2010

\begin{tabular}{llll}
\hline Collision level & Number of spills & $\begin{array}{l}\text { Probability } \\
\text { spillage }\end{array}$ & of \\
\hline Total loss & 3 & 0.43 & $4.0 \mathrm{E}-05$ \\
Majority & 33 & 0.15 & $4.4 \mathrm{E}-04$ \\
General & 3 & 0.03 & $4.0 \mathrm{E}-05$ \\
Total accidents & 39 & 0.12 & $5.2-04$ \\
\hline
\end{tabular}

It can be seen from Table 1 that the probability of oil spill is not very high in collision accidents. The frequency of oil spill of different types of ships after collision is: concentrated container ship > General cargo 
ship > bulk cargo ship > General cargo ship > chemical transportation products > cruise ship > other ships > fishing boat (Morris et al., 2018). After the oil spill accident, the amount of oil spill is directly related to the size of the ship. The relationship between the probability of oil spill and the oil spill volume and tonnage is as follows:

$$
K\left(\frac{\tau}{\gamma}\right)=0.01-0.21 \log \left(\frac{\tau}{\gamma}\right)
$$

In the formula, $K$ represents oil spill, $\tau$ represents the load of a ship, $\gamma$ represents the cumulative probability of oil spill, which is greater than the amount of oil spilled, and the value range is between [0-1]. When a ship collides, there is a direct relationship between the transportation status and the oil spill probability. It is assumed that $50 \%$ of the time of the ship is empty and the other $50 \%$ of the time is full load:

$$
Y=\frac{N_{\text {happen }}}{\omega_{\text {total }}} \times R_{i} \times \alpha_{j}
$$

In the formula, $N_{\text {happen }}$ representing the total number of collision accidents, $\omega_{\text {total }}$ representing the total number of cruise ships sailing in the South China Sea region, $\alpha_{j}$ represents the ship's oil spill probability.

After analyzing the probability of oil spill in the South China Sea navigation area, the area of oil spill pollution and the pollution of the South China Sea navigation area are evaluated. Build the assessment system of oil spill pollution, obtain the weight of each impact factor, etc. (Łazuga et al., 2018). Based on this, build the assessment model of sudden oil spill pollution, and evaluate the pollution situation of navigation area in South China Sea.

\section{Evaluation model of sudden oil spill pollution from ships in South China Sea Navigation Area}

\subsection{Construction of marine spill pollution evaluation system}

Based on the probability of ship oil spill in the South China Sea navigation area, the evaluation index system of oil spill pollution in this area is constructed, and the pollution degree of the area is evaluated. The evaluation system of ship oil spill pollution is shown in Figure 2: 


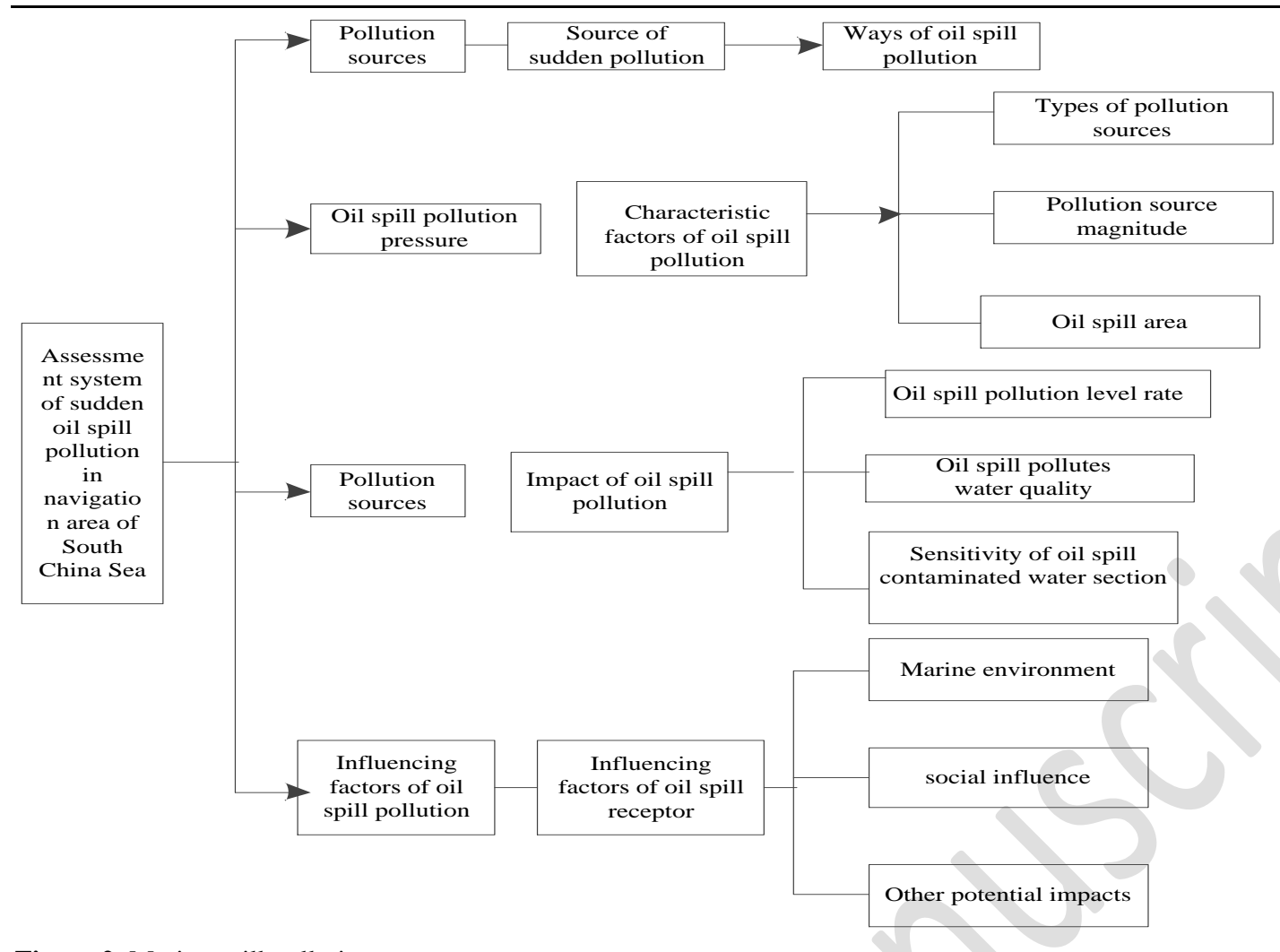

Figure 2. Marine spill pollution assessment system

After the establishment of the assessment system of sudden oil spill pollution in the South China Sea navigation area, the pollution sources of sudden oil spill are obtained. Firstly, the pollution source magnitude of ship oil spill is obtained (Yu et al., 2020). In the case of sudden oil spill pollution from ships in the South China Sea navigation area, in order to control the pollution scope, the traffic flow of the channel should be controlled under the condition of ensuring the normal operation of the channel. However, due to the obstruction of the water environment, it is impossible to realize the segmented control of the water area, and the sudden pollution control is not timely reflected and the control effect is not good. The index of pollution source magnitude is put forward in combination with the regional regulation of navigation in the South China Sea. The types of oil spill pollutants are divided into floating oil and soluble pollutants. Considering the characteristics of the South China Sea navigation area and the types of pollutants, the pollution source magnitude of sudden oil spill pollution types is calculated (Spaulding, 2017).

The magnitude of floating pollution is obtained by formula (7):

$$
\sigma_{\text {oil }}=\frac{v_{\text {oil }}}{v_{\text {water }}}
$$

In the formula, $v_{\text {oil }}$ represents the maximum oil film area formed by sudden ship oil spill pollution, $\mathrm{m}^{2}$,

$v_{\text {water }}$ representing the surface area of water bodies in areas contaminated by oil spills, $\mathrm{m}^{2}$.

The magnitude of soluble pollutants is calculated according to ship collision, capsizing,

$$
\beta_{\text {oil }}=\frac{10^{6} H}{V} / \mu_{t}
$$

In the formula, $H$ represents the total risk of potential sudden oil spill pollution, $V$ representing the 
navigation area where the pollution risk is located, $\mu_{t}$ represents the water purity of the polluted watershed under normal conditions.

Considering that the ship may capsize when sailing in the South China Sea, resulting in sudden oil spill pollution, the polluted water area will continue to expand, at this time, the pollution magnitude of the water area is calculated as follows:

$$
I_{o i l}=\frac{B_{t} C_{t}+B_{l} C_{l}}{B_{t}+B_{l}}
$$

In the formula, $B_{t}$ and $C_{t}$ representing the total amount of pollution from sudden ship oil spill, $B_{l}$ and

$C_{l}$ represent the concentration of the flow pollution index of sudden ship oil spill pollution.

In the navigation basin of the South China Sea, the elevation of the basin becomes an important factor affecting the pollution diffusion when oil spill occurs. In case of sudden oil spill pollution at high terrain, it will flow back to the low-lying area rapidly, resulting in the pollution in the navigation area of the South China Sea will continue to expand:

$$
G_{i}=\frac{B_{t} C_{t}+\vartheta \Delta t C_{j}}{V+\vartheta \Delta t}
$$

In the formula, $\vartheta$ represents the amount of pollution that the elevation basin enters the lower reaches of the low-lying basin. $\Delta t$ represents the duration of the flow in the elevation basin, $C_{j}$ represents the pollution concentration of sewage index in elevation waters.

\subsection{Evaluation model of oil spoil pollution}

Based on the above evaluation system of oil spill pollution from ships and obtaining the pollution magnitude, the assessment model of oil spill is constructed. Firstly, the weight of risk index is determined. The determination of weight can reflect the important comprehensive measurement process of subjective evaluation of sudden oil spill pollution. In this paper, the judgment matrix of the criterion level and the index level is constructed:

$$
F=\left[\begin{array}{l}
f_{11}, f_{12} \ldots f_{1 n} \\
f_{21}, f_{22}, \ldots f_{2 n} \\
\ldots \\
f_{n 1}, f_{n 2}, \ldots f_{n n}
\end{array}\right]
$$

In the formula, $f_{n n}$ represents the importance of pollutants in the navigation basin.

According to the constructed judgment matrix, the maximum eigenvalue $\chi_{\max }$ and eigenvector of pollution are obtained, After normalization, the consistency index of judgment matrix is calculated, and the proportion of consistency index is as follows:

$$
Z I=\frac{\chi_{\max }-n}{n-1}
$$




$$
Z R=\frac{Z I}{R I}
$$

In the formula, when $Z I \leq 0.1$, the judgment matrix has good consistency, when $Z I>0.1$, the consistency of the judgment matrix is poor. When $Z I \leq 0$, it is considered that the distribution of weight is more reasonable and effective. On the premise that the judgment matrix meets the requirements of consistency, the evaluation weight value of ship sudden oil spill pollution is calculated

$$
\psi_{i}=\sqrt[n]{\prod_{i=1}^{n} B_{t}}
$$

Among them, the formula for calculating the global weight of each index of pollution is:

$$
W_{i k}=k W_{i} \times k W_{i k}
$$

After obtaining the weight of the assessment of the sudden ship pollution in the South China Sea navigation area, the comprehensive evaluation model of the risk level of the sudden ship oil spill pollution is constructed according to the pollution weight

$$
U=\sum_{i, j=1}^{n} W_{i, i j} \times \varsigma_{i}
$$

In the formula, $U$ represents the risk value of sudden ship oil spill pollution, $W_{i, i j}$ represents the weight of each pollution indicator, $\varsigma_{i}$ represents the calculated value of individual index pollution.

\section{Experimental analysis}

In order to verify the evaluation performance of the model constructed in this paper, the experimental analysis is carried out. The method of this paper, the method in Sha et al. (2018) and Zhang et al. (2018)'s studies were compared to evaluate the pollution of the experimental area.

\subsection{Experimental environment}

In the experiment, the area with sudden oil spill pollution in the South China Sea navigation area was selected. The pollution area was $100 \mathrm{~m}^{2}$. The data was analyzed by using SPSS. 13.0 software, and the pollution data was input into the experimental analysis system reference system for preprocessing. The experimental pollution area is shown in Figure 3. 


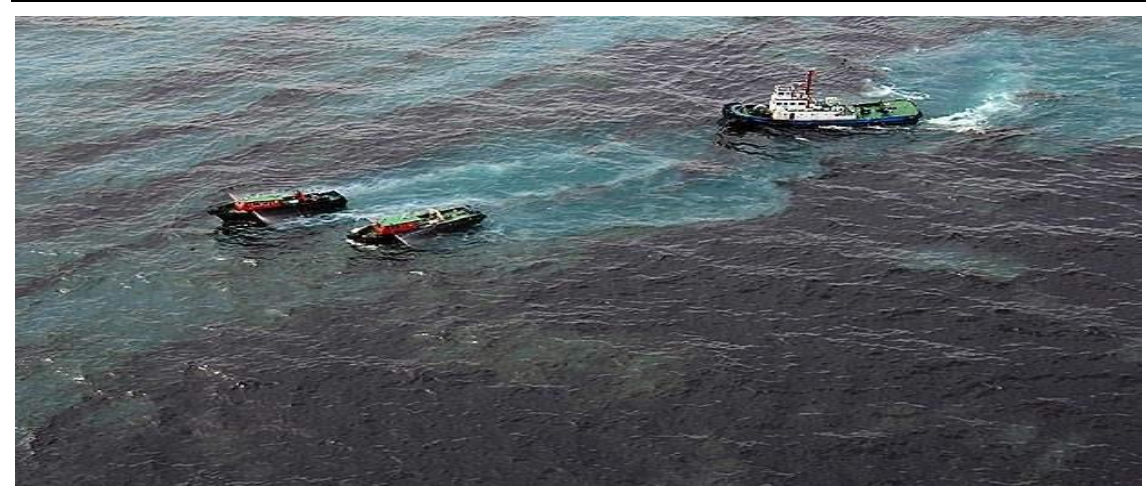

Figure 3. Experimental environment

\subsection{Experimental parameters}

The experimental parameters are shown in Table 2:

Table 2. Experimental parameters

\begin{tabular}{ll}
\hline Parameters & Value \\
\hline Regional flow rate $/ \mathrm{m} / \mathrm{s}$ & 5 \\
Oil spill spread rate $/ \mathrm{m} / \mathrm{s}$ & 5 \\
Marine area contaminated area $/ \mathrm{m}^{2}$ & 85 \\
Number of iterations/times & 20 \\
Sampling interval/s & 10 \\
\hline
\end{tabular}

Under the above experimental environment and experimental parameters, the evaluation accuracy and evaluation time are used as experimental indicators to verify the scientific effectiveness of the proposed method.

\subsection{Analysis of experimental results}

\subsubsection{Precision analysis of pollution assessment in different methods}

In the assessment of sudden oil spill pollution, it is an important target to measure the accuracy of the assessment. The accuracy of this method, the method in Zhang et al. (2018) and Liu et al. (2019)'s studies are compared in the experiment. The experimental results are shown in Figure 4:

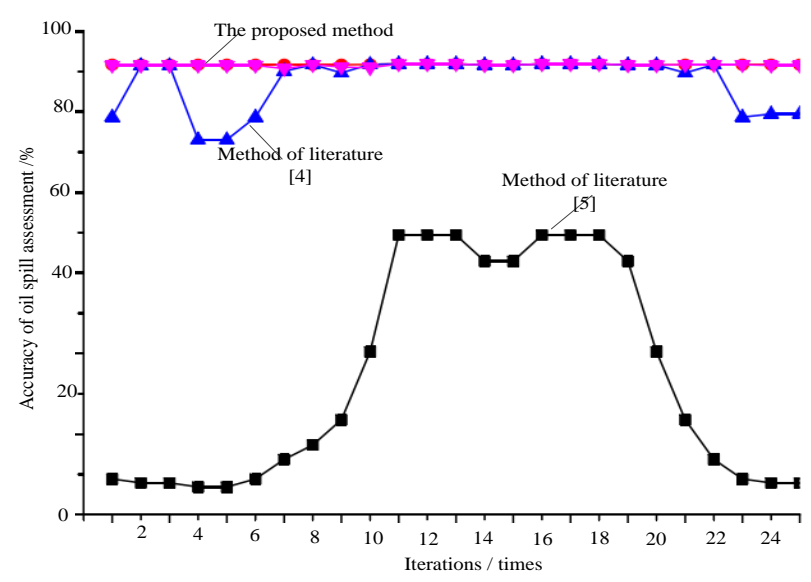

Figure 4. Comparison of pollution assessment accuracy of different methods 
It can be seen from Figure 4 that under the same experimental conditions, with the continuous change of iteration times, the accuracy of the three methods for pollution assessment has a certain change. Among them, the evaluation accuracy of the proposed method is relatively stable, which is maintained at about $90 \%$. The stability of the evaluation accuracy of the methods in Sha et al. (2018) and Zhang et al. (2018)'s studies is poor, and the average evaluation accuracy of the two methods is lower than that of the proposed method. This is because the proposed method improves the scientific effectiveness of the proposed method by analyzing the index system of sudden oil spill from ships in the South China Sea and calculating the pollution weight.

\subsubsection{Time-consuming analysis of different methods of pollution assessment}

In order to further verify the scientific effectiveness of the proposed method, on the basis of ensuring the accuracy of pollution assessment, the time consumption of the proposed method, the method in Sha et al. (2018) and Zhang et al. (2018)'s studies are compared:

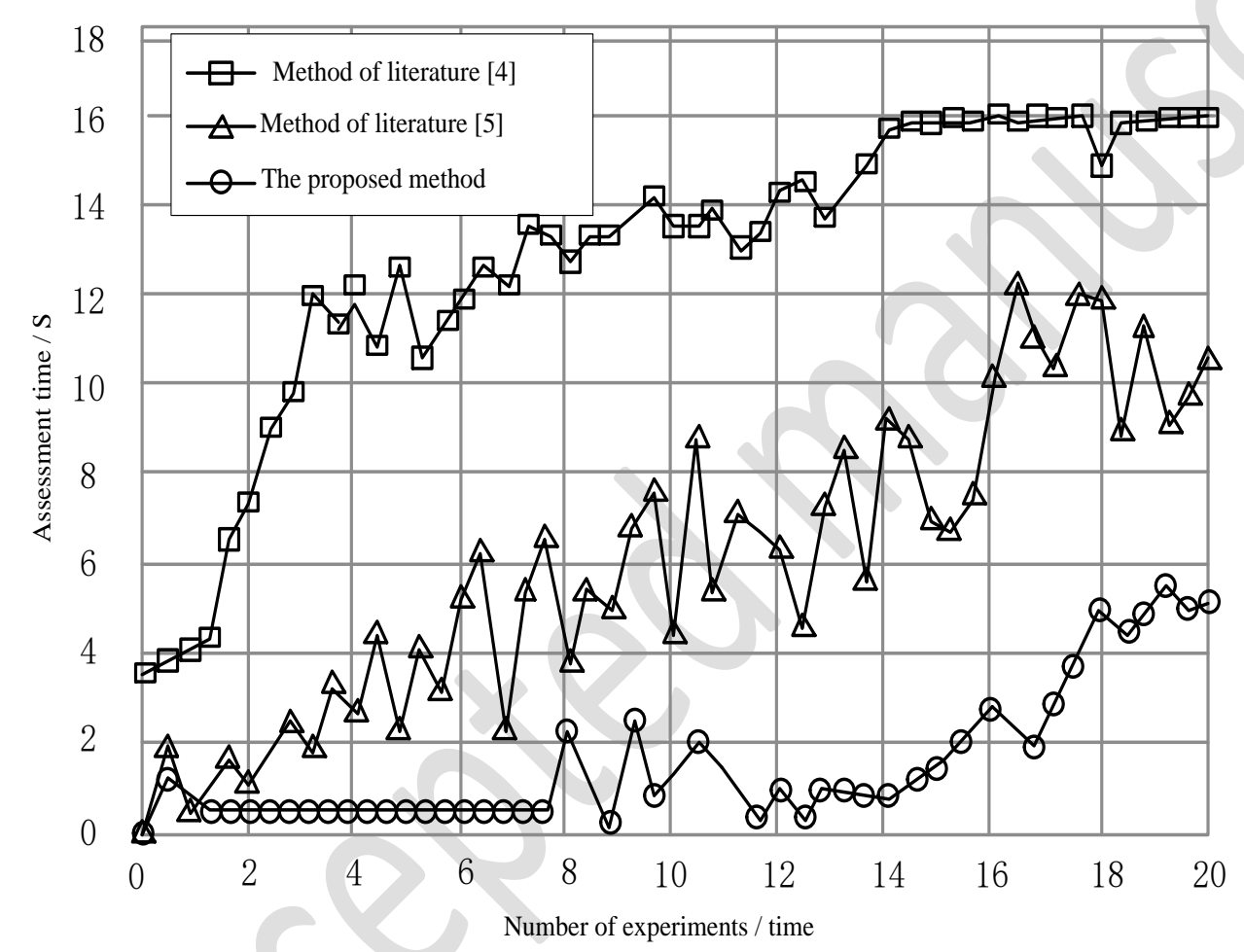

Figure 5. Comparison of pollution assessment time

It can be seen from Figure 5 that with the change of the number of experiments, the proposed method, the method in Sha et al. (2018) and Zhang et al. (2018)'s studies take different time to evaluate the pollution. Among them, the evaluation time of the proposed method is about $5 \mathrm{~s}$, that of in Sha et al. (2018)'s study is about $16 \mathrm{~S}$, and that of Zhang et al. (2018)'s study is about $12 \mathrm{~s}$. Compared with the straight line method, the proposed method takes the shortest time, which verifies the scientific effectiveness of the proposed method.

\section{Conclusion}

Based on the analysis of the transportation advantages of the South China Sea navigation area, this paper proposes to build the assessment model of sudden oil spill pollution in the South China Sea navigation area under the theory of community of destiny. Based on the analysis of the transportation advantages of the 
South China Sea navigation area, the probability of ship collision and the relationship between the probability of ship oil spill and the ship tonnage are obtained. Based on the probability of ship oil spill in the South China Sea navigation area, the evaluation index system of oil spill pollution in the South China Sea navigation area is constructed to determine the oil spill pollution index and pollution level, and to determine the oil spill pollution level The weight of oil pollution index is used to build the assessment model of sudden oil spill pollution in South China Sea navigation area. Compared with traditional methods, the proposed method has the following advantages:

(1) The accuracy of the proposed model is always maintained at about $90 \%$, which has a certain credibility.

(2) The time-consuming and efficiency of the proposed model is relatively high.

The model constructed in this paper seems to be effective at this stage, but there are still some defects. In the construction of the pollution index system, less factors are considered. Future research will focus on this part of the content, in order to continuously improve the scientific nature of the article.

\section{Acknowledgement}

The research is supported by: A study on freedom of navigation in the south China sea from the perspective of Ocean Destiny Community (National Social Science Fund Youth Project, 2018, 18CFX082)

\section{References}

Bayik DG, Altin A. Production of sorbent from paper industry solid waste for oil spill cleanup. Marine Pollution Bulletin, 2017, 125(12):341-349.

Dong F, Zhu XS, Wang JX, et al. Research progress in ecotoxicology of climate change coupled with marine pollutions. Chinese Science Bulletin, 2018, 63(5):521-534.

Gan JL, Gu XL, Li LD, et al. Oil pollution and its relation to marine economy along Guangdong province coast of china during 2001-2010 based on oyster as a bio-indicator. Journal of Ecology and Rural Environment, 2018, 34(10):897-902.

He L, Shen J, Zhang Y. Ecological vulnerability assessment for ecological conservation and environmental management. Journal of Environmental Management, 2018, 206:1115-1125.

Jing YT, Li ZL, Zhang CS, et al. Preliminary study on biological amplification effect and the enrichment specificity of oil-spill pollutants in different tissues of chlamys farreri. Asian Journal of Ecotoxicology, 2019, 14(1):135-141.

Łazuga, Kinga, Gucma L, Perkovic M. The model of optimal allocation of maritime oil spill combat ships. Sustainability, 2018, 10(7):14-20.

Li J, Sun ZG, Sun WL, et al. Assessment of pollution and potential ecotoxicity risk for heavy metals in sediments in the tail reach and estuary of the Yellow River. Wetland Science, 2018, 16(3):407-416.

Liu WF, Liu DH, Xing WX, et al. Identification and assessment index of direct losses caused by marine environmental pollution. Marine Environmental Science, 2019, 38(1):120-128.

Liu X, Guo M, Wang Y, et al. Assessing pollution-related effects of oil spills from ships in the Chinese Bohai Sea. Marine Pollution Bulletin, 2016, 110(1):194-202.

Morris L, O'Brien A, Natera SHA. Structural and functional measures of marine microbial communities: An experiment to assess implications for oil spill management. Marine Pollution Bulletin, 2018, 131(7):525-529.

Sha JJ, Li YR, Wang CH, et al. Study on the environmental assessment approaches of marine oil spill pollution based on biomarkers. Marine Science Bulletin, 2018, 37(5):506-514. 
Spaulding ML. State of the art review and future directions in oil spill modeling. Marine Pollution Bulletin, 2017, 115(1-2):7-15.

Toz AC, Koseoglu B. Trajectory prediction of oil spill with Pisces 2 around Bay of Izmir, Turkey. Marine Pollution Bulletin, 2018, 126(11):215-227.

Wang S, Zhang K, van Beek LPH, et al. Physically-based landslide prediction over a large region: Scaling low-resolution hydrological model results for high-resolution slope stability assessment. Environmental Modelling \& Software: With Environment Data News, 2020, 124:104607.

Wang X, Li SD, Liu HH, et al. Spatiotemporal distribution characteristics of soil erosion in the lower reaches of the Chishui River Basin, China. Applied Ecology and Environmental Research, 2020, 18(3):4449-4467.

Xue X, Ma QM, Ding HP, et al. Change of oil fingerprint parameters of surface sediment in the southern coastal of Jiaozhou Bay. Environmental Chemistry, 2018, 37(2):310-317.

Yang C, Gao F, Dong M. Energy efficiency modeling of integrated energy system in coastal areas. Journal of Coastal Research, 2020, 103(sp1):995.

Yu D, Mao Y, Gu B, et al. A new LQG optimal control strategy applied on a hybrid wind turbine/solid oxide fuel cell/ in the presence of the interval uncertainties. Sustainable Energy, Grids and Networks, 2020, 21:100296.

Zhang CC, Liu BZ, An W, et al. Oil spill pollution risk assessment in Xiaohu petrochemical port area of Guangzhou based on index method. Ship \& Ocean Engineering, 2019, 48(1):172-176.

Zhang K, Liu XJ. Evaluation on oil spill pollution level of offshore oil platform based on improved AHP and extension theory. Journal of Shanghai Maritime University, 2018, 39(1):98-103. 